\title{
МАРКЕТИНГОВЫЕ СОБЫТИЯ В ЗДРАВООХРАНЕНИИ: ОСОБЕННОСТИ И ЭФФЕКТИВНОСТЬ
}

\author{
(c) 2021 Зубарева Наталья Николаевна \\ кандидат педагогических наук, соискатель, Кафедра менеджмента и маркетинга \\ Белгородский государственный национальный исследовательский университет, Россия, Белгород \\ E-mail nzubareva73@mail.ru
}

\section{(C) 2021 Луговская Мария Владимировна}

кандидат экономических наук, старший преподаватель, Кафедра менеджмента и маркетинга Белгородский государственный национальный исследовательский университет, Россия, Белгород

E-mailkmari5@mail.ru

Современные события в здравоохранении указывают на наличие определенной специфики в маркетинговой деятельности. В частности, все более актуальным становится поисковый маркетинг. Проведено исследование потребительского рынка, нацеленное на выяснение и популяризацию цифрового маркетинга в сфере здравоохранения. Даны пояснения и рекомендации по преодолению сложностей во внедрении маркетинговых мер, и их эффективность.

Ключевые слова: маркетинг, оптимизация, поисковый маркетинг, цифровой маркетинг, маркетинговая информационная система.

Введение. Современные изменения в системе здравоохранения связаны с ситуацией, возникшей в условиях пандемии. Происходящие изменения в сознании населения привели к росту спроса на медицинские услуги. Наблюдается спрос на информационную обеспеченность системы здравоохранения, которая служит проводником между населением и медициной. С другой стороны, каждый из нас, достаточно емко информирован и источников современных данных более чем достаточно в СМИ. Конкуренция на рынке медицинских услуг возрастает, не смотря на тот же производственный баланс в компаниях реализующих данного типа услуги. В современных условиях наиболее наглядно прослеживается взаимосвязь государства, потребителя и учреждений здравоохранения. Поэтому в складывающихся условиях все большую актуальность составляют маркетинговые исследования, нацеленные на отслеживание уровня взаимодействия между тремя компонентами современной системы. Что, в последующем, способно оказать влияние на реформу здравоохранения и изменение психологии восприятия медицинских показателей со стороны потребителя.

\section{Материалы и методы}

Особенности интерпретации современных событий в медицине предполагают лишь повышение эффективности действий со стороны маркетинга. Так или иначе, к маркетинговым

событиям следует отнести полную взаимосвязь трех компонентов системы с последующим эффективным взаимодействием. Особенность данного взаимодействия состоит в полной взаимовыгоде, как для государственного сектора, так и для медицины, но главная выгода состоит в получении достойных результатов пациентами.

Обсуждение.

На рис. 1 рассмотрена роль маркетинга в системе здравоохранения. Учреждения здравоохранения, в условиях острой необходимости применения маркетинговых технологий, формируют конкурентные позиции с целью тотального взаимодействия не только с потребителем, но и с участниками государственного сектора.

Тем самым складывается ситуация, когда главной проблемой медицинского учреждения становится оптимизация объема и структуры потребления медицинских услуг как в интересах каждого индивидуума, так и в интересах общества в целом [10].

Поскольку здравоохранение имеет своей целью удовлетворение общественных и личных нужд, то для его успешной деятельности потребности общества и людей должны быть изучены, спрогнозированы возможные их изменения. Достичь поставленных целей помогает маркетинг, обеспечивая учреждения здравоохранения необходимыми методами сбора и анализа информации [3,12]. 

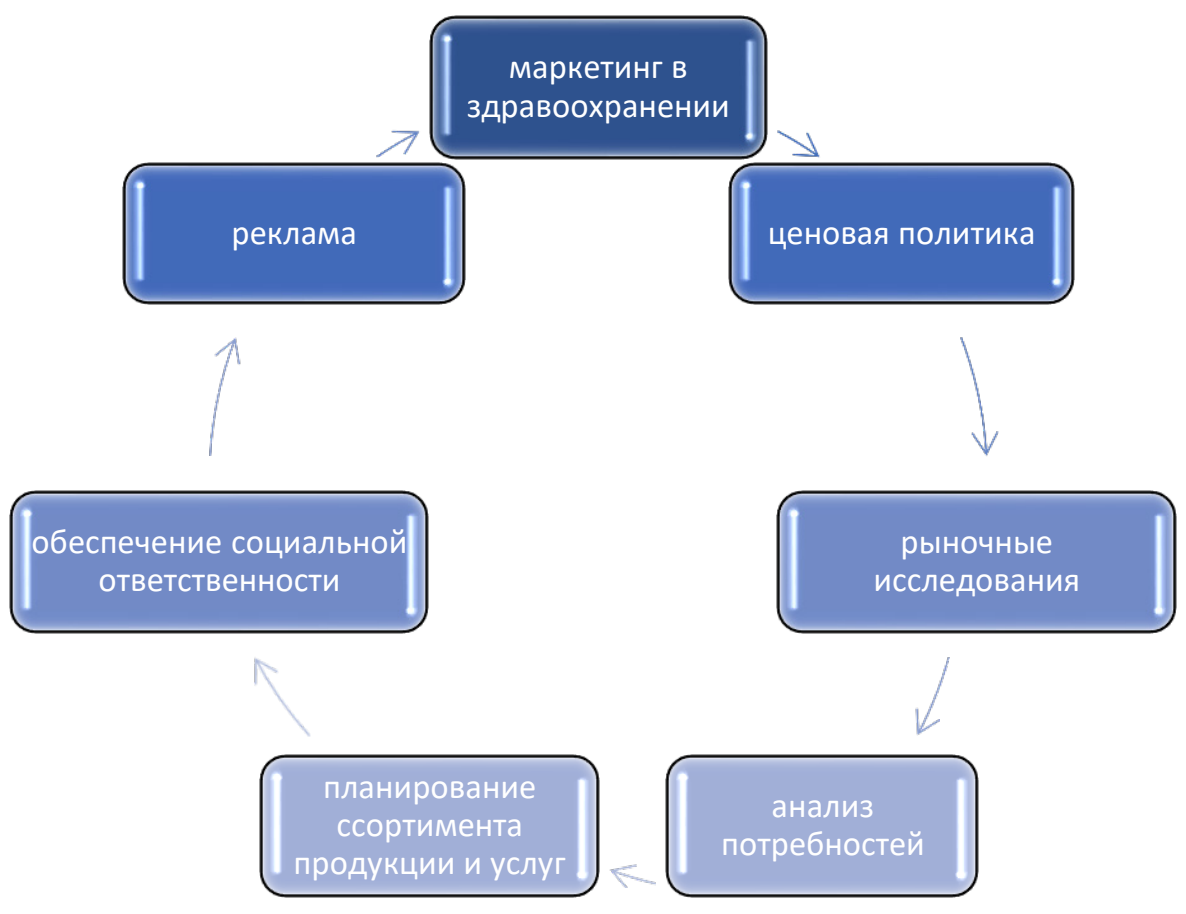

Puc. 1. Роль маркетинга в здравоохранении

Правильным становится отражение внутреннего взаимодействия между тремя участниками современной ситуации.

В кризисных условиях пандемии коронавируса участники рынка вынуждены искать новые формы взаимодействия (рис. 2), нацеленные на преодоление возникшей ситуации, путем совместного удовлетворения потребностей всех трех сторон. Маркетинговые события в этой части связаны с возрастающим спросом как на информационные ресурсы, так и на качественные услуги и приобретение необходимых средств защиты.

Исходя из современной ситуации в условиях пандемии самыми правильными методами воздействия на систему здравоохранения являются такие маркетинговые события, как увеличение информационной активности потребителяпациента, соответственно увеличение спроса на поисковый маркетинг. В кризисных условиях пандемии коронавируса участники рынка вынуждены искать новые формы и методы продвижения корпоративных продуктов и услуг в интернете.

\section{Результаты.}

Поэтому, основополагающим методом взаимодействия является правильно построенные маркетинговые коммуникации. Нами предлагается следующая модель структурного взаи- модействия с целью построения эффективных стратегий дальнейшего развития системы здравоохранения. Так, пандемия создала определенные условия как для государственного сектора, для здравоохранения, но главным образом для общества. Ввиду имеющихся обстоятельств, правильным будет решение, в результате которого, несмотря на условия, локальное взаимодействие будет налажено. Данное взаимодействие отражено на рис. 3.

\section{Заключение.}

Таким образом, маркетинговые события в сфере здравоохранения нацелены на удовлетворение потребительского спроса, но имеют ряд специфических особенностей. Ведь медицинские услуги - это не извлечение совокупной выгоды из оказываемых услуг, а в первую очередь, это вид полезной деятельности, оказываемой с целью оказания помощи. Следовательно, все происходящие вокруг медицины мероприятия, ни что иное как маркетинговая деятельность ориентированная на повышение осязаемости предлагаемых услуг.

Маркетинговые события в учреждениях здравоохранения, не зависимо от способа реализуемой деятельности - коммерческие или некоммерческие, будут способствовать повышению конкурентоспособности, не только предлагаемых услуг, но и самого учреждения. 


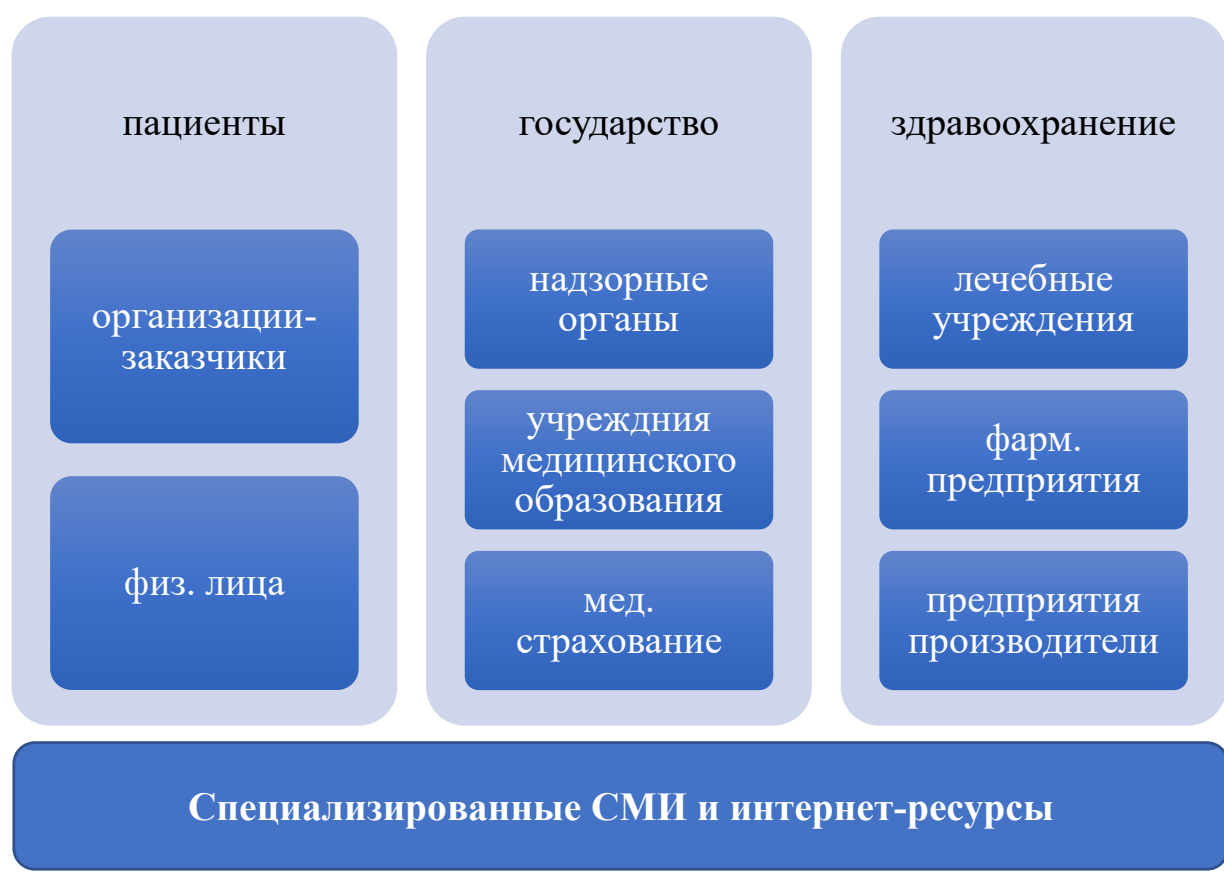

Puc. 2. Схема взаимодействия государства, общества и здравоохранения

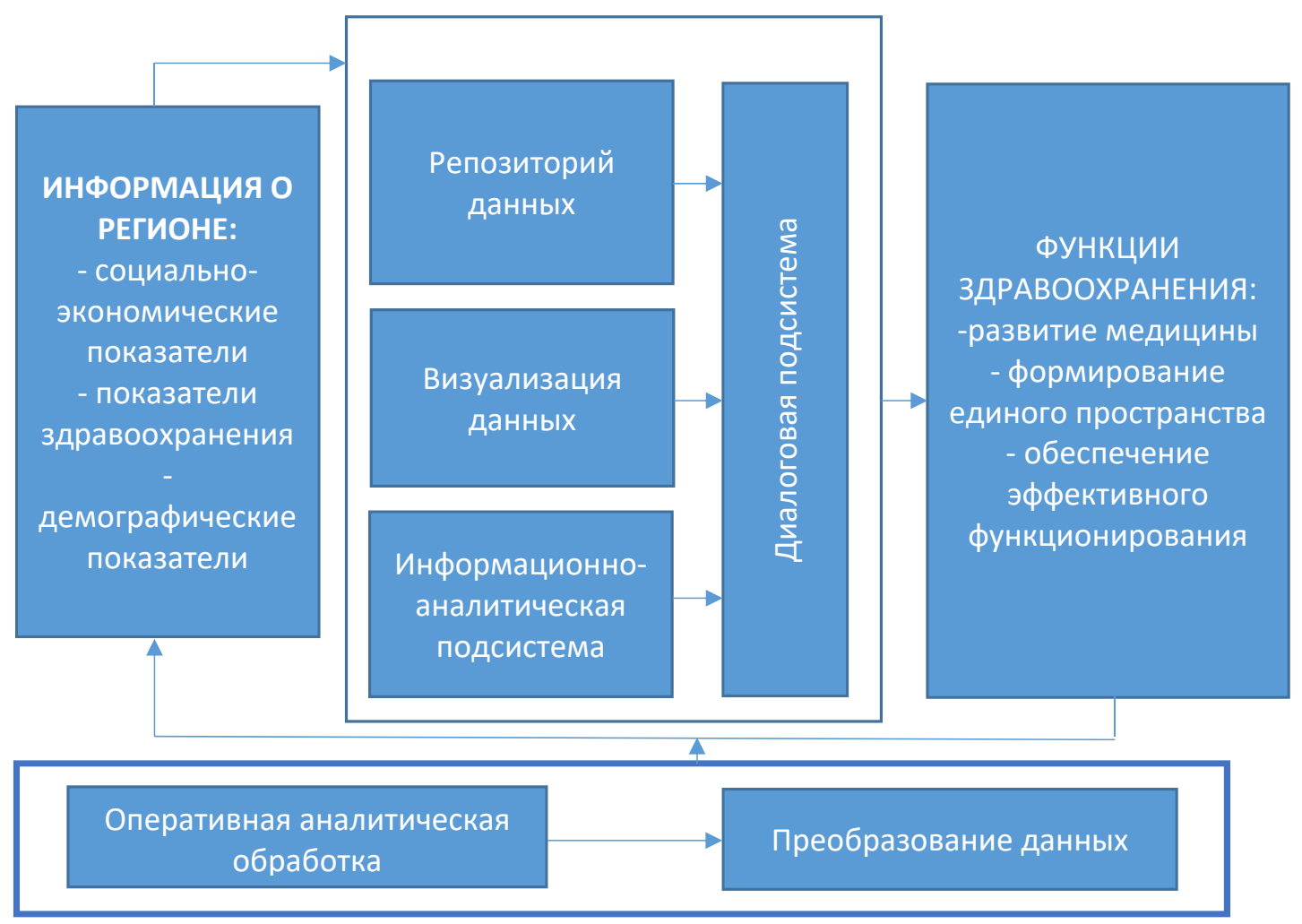

Puc. 3. Модель построение маркетинговой концепции во взаимодействии 


\section{Библиографический список}

1. Анохин Е.В., Анохин В.А. Маркетинговая информационная система в управлении территориями // Инновации. - 2019. - № 5.- С. 61-68.

2. Бикметов Е.Ю., Гумерова З. Ж., Рувенный И. Я. Социально ориентированный маркетинг в управлении проектами высокотехнологичных медицинских инноваций // Вестник Пермского национального исследовательского политехнического университета. Социально-экономические науки. - 2020. - № 2.- С. 303-316.

3. Бондаренко В.А. Апология маркетинга в кризисных условиях // Маркетинг в России и за рубежом. - 2010.№ 4.- С. 3-9.

4. Бондаренко В.А. Вопросы адекватности менеджмента современным экономическим реалиям: корневые причины и основные тенденции // Менеджмент в России и за рубежом.-2013. - № 5. - С. 118-125.

5. Бондаренко В.А., Иванченко О.В.Вопросы формирования информационно-коммуникационной инфраструктуры маркетинга на основе исследования потребностей целевых сегментов (на примере локального рынка) // Конкурентоспособность в глобальном мире: экономика, наука, технологии. - 2017. - № 2-3 (31).C. $22-26$.

6. Бурмистрова И.К., Кублин И.М. Рынок В2В - современные формы сотрудничества и развития // Наука и общество. - 2018. - № 2 (31). - С. 9-13

7. Воронов А.А., Валькович О.Н. Рыночный подход - единственно реальный путь повышения качества и эффективности медицинского обслуживания в современной России // Проблемы управления здравоохранением. - 2002. - № 2.- С. 44-47.

8. Воронов А.А., Валькович О.Н. Рыночный подход путь повышения качества медицинского обслуживания // Здравоохранение Российской Федерации. - 2001.- № 5.-С. 6-8.

9. Воронов А.А., ЕрокА.Д., ШтезельА. Ю. Локальные рынки: маркетинг и стратегия. Монография. Краснодар, ККИ РУК, 2019.- 161 с.

10. Высочин В.В., Багова Ф.Р., Гарьковенко В.Э. Государственно-частное партнерство: сущность, цели, задачи, условия эффективности // Электронный сетевой политематический журнал «Научные труды КубГТУ».2015. - № 2.- С. 163-170.

11. Кемалов Р.Ф. Маркетинговая сущность отношений в медицинской деятельности// Сибирский медицинский журнал. - 2006. - Т. 59. - № 1.- С. 86-90.

12. Кублин И. М. Маркетинг в системе управления конкурентоспособностью продукции // Поволжский торговоэкономический журнал. - 2013. - № 2 (30). - С. 52-60.

13. Кублин И.М., Плеханов С. В., Канщлер Э. Э. Применение цифровых технологий в сфере продвижения рекламной продукции // Актуальные проблемы экономики и менеджмента. - 2020. - № 2 (26). - С. 67-76.

14. Олейник M.В., Страхова О.А. Маркетинг взаимодействия как фактор повышения конкурентных преимуществ медицинских фирм и учреждений // Известия Санкт-Петербургского государственного университета экономики и финансов. - 2009. - № 1.- С. 53-57.

15. Синяева И. М. Преодоление факторов пандемии с помощью инструментов поискового маркетинга // Образование. Наука. Научные кадры. - 2021. - № 1.- С. 118-121. 